Discussion

\title{
Microbiomes, metagenomics, and primate conservation: New strategies, tools, and applications
}

\author{
R.M. Stumpf ${ }^{\mathrm{a}, \mathrm{b}, *}$, A. Gomez ${ }^{\mathrm{c}}$, K.R. Amato ${ }^{\mathrm{d}}$, C.J. Yeoman ${ }^{\mathrm{e}}$, J.D. Polk ${ }^{\mathrm{b}}$, B.A. Wilson ${ }^{\mathrm{a}}$, K.E Nelson ${ }^{\mathrm{c}}$, \\ B.A. White ${ }^{\mathrm{a}}$, S.R. Leigh $^{\mathrm{f}}$
}

a C.R. Woese Institute for Genomic Biology, University of Illinois at Urbana Champaign, IL 61801, USA

b Department of Anthropology, University of Illinois at Urbana Champaign, IL 61801, USA

c Department of Human Biology, J. Craig Venter Institute, La Jolla, CA 92037, USA

d Department of Anthropology, Northwestern University, Evanston, USA

e Department of Animal and Range Sciences, Montana State University, Bozeman, MT 59717, USA

${ }^{\mathrm{f}}$ Department of Anthropology, University of Colorado, Boulder, CO 80309, USA

\section{A R T I C L E I N F O}

\section{Article history:}

Received 10 November 2015

Received in revised form 19 March 2016

Accepted 30 March 2016

Available online 14 May 2016

\begin{abstract}
A B S T R A C T
Conservation strategies require multifaceted approaches to monitor and protect primate populations, many of which are rapidly declining around the world. We propose that microbial ecology and next-generation microbiome analyses offer valuable perspectives and tools for investigating and monitoring primate health and improving conservation efforts. The microbial communities inhabiting primates and other taxa profoundly affect host health, nutrition, physiology, and immune systems, through relationships that range from commensal and mutualistic to pathogenic. Recent advances in DNA sequencing now make it feasible and economically viable to identify microbiomes among and within hosts. Herein, we highlight several examples in which microbial analyses of primates can aid conservation approaches that are broadly applicable across other taxa. First, we highlight evidence for clear spatial variation (e.g. biogeographic niche specificity, both within the anatomical regions of the host body, as well as in the geographic location of the host) and temporal (e.g. seasonal, ontogenetic) patterns in microbial distribution. We emphasize that microbial communities are sensitive to alterations in the external environment and that microbial diversity correlates with habitat quality, imposing direct health consequences. Incorporating microbial host and biogeographic variation holds great potential for forest corridor assessments and for reintroduction efforts. Finally, microbial pathogens transmitted between humans and wild primate populations carry both direct and indirect conservation implications. Principally, we argue that phylogenetic analyses of infectious pathogens (e.g., Ebola, dengue, Borellia, and Treponema) can aid our understanding of modes of disease transmission and aid conservation disease abatement efforts. The application of microbial analyses to conservation is currently in its infancy but holds enormous potential. To date, no conservation policy or legislation includes microbiome assessments. Integrating new understanding of the patterns of microbial diversity and early signs of impending microbial disruption offer valuable tools for informing conservation strategies and monitoring and promoting primate (including human) health.
\end{abstract}

(c) 2016 Elsevier Ltd. All rights reserved.

\section{Introduction}

The world's primates currently face enormous ecological pressures (Cowlishaw and Dunbar, 2000; Estrada, 2013; Benchimol and Peres, 2014). Many species are critically endangered, and populations are declining rapidly (Walsh et al., 2003). Primate conservation is a complex and multifaceted challenge. Contributing factors are linked to the

\footnotetext{
* Corresponding author at: Carl R. Woese Institute for Genomic Biology, The University of Illinois, 1206 West Gregory Avenue, Urbana, IL 61801, USA.

E-mail address: rstumpf@illinois.edu (R.M. Stumpf).
}

rapidly expanding human population and anthropogenic activities, such as logging, large-scale agriculture, and cattle ranching (Estrada, 2013). Tropical range countries of West Africa, Indonesia, and South America hold some of the highest levels of plant and animal biodiversity, yet are also experiencing some of the highest rates of deforestation (Fig. 1). These changes in the tropics are catastrophic for primate biodiversity, as these ranges represent their primary habitat, leading to adverse conservation outcomes.

Current wildlife conservation strategies include establishing national parks and protected areas, anti-logging and anti-poaching regulations, incentives for local conservation, captive breeding and reintroduction 
A

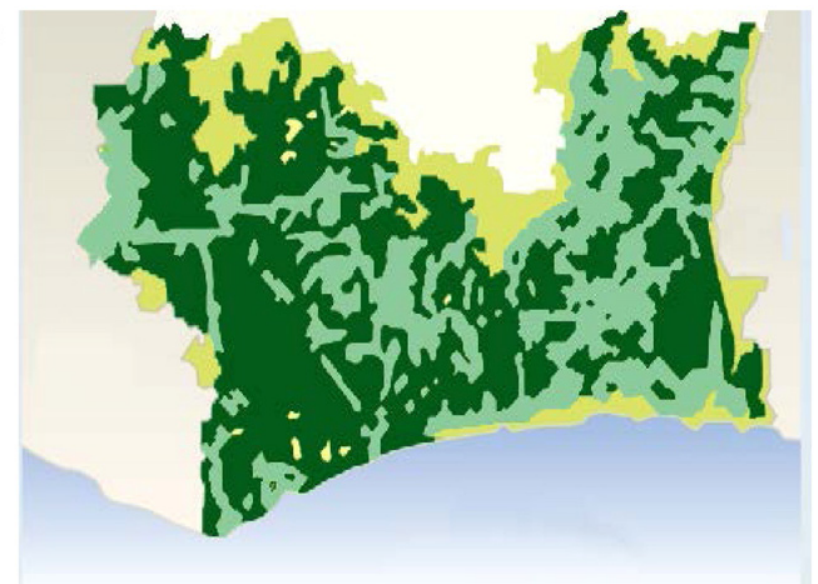

B

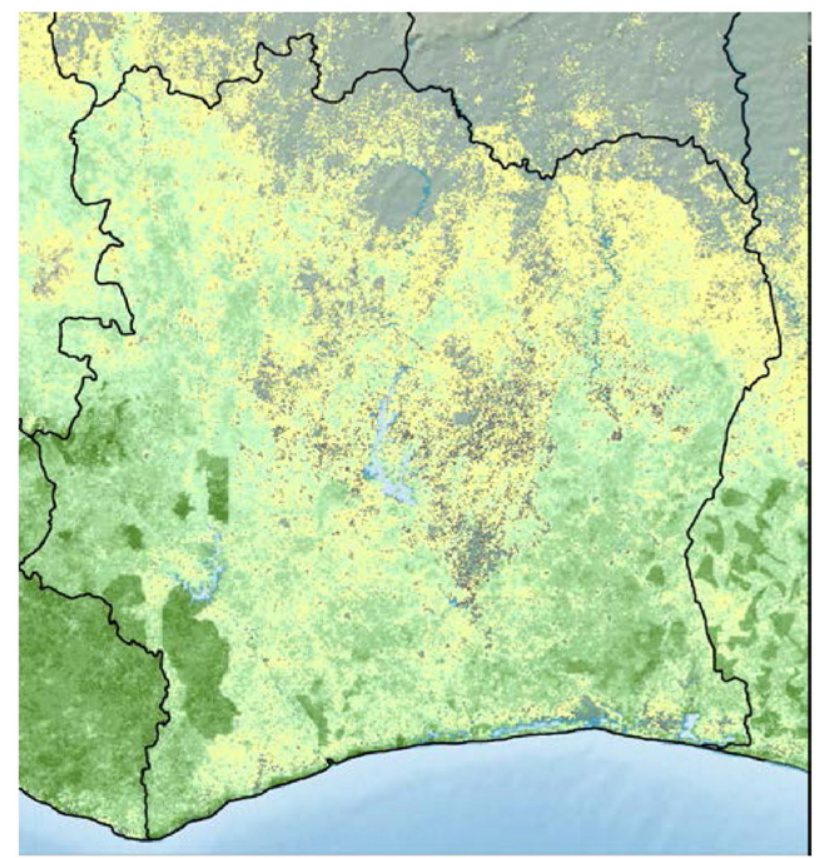

Fig. 1. Rapid reduction in the forest cover of Côte d'Ivoire from 1955 (A) through 2010 (B) largely due to Western interests. Dark green indicate more continuous forest cover, yellow is open country. Continuous forest remains only in very limited, protected areas such as the Taï Forest. Image A is from (http://www.grida.no/); B is modified from data at www.fao.org.

programs. More recently, the application of tools such as geographic information systems (GIS) and camera traps to conservation challenges holds great potential for understanding patterns of habitat variation, usage, and population densities. However, these strategies had mixed results. Increasingly, effective conservation strategies require integrated solutions at the macro- and micro-ecological levels.

Analyses of primate microbiomes are emerging as a suite of novel tools that have great potential for supporting conservation efforts. The primate body hosts trillions of microbial cells (Savage, 1977; Gill, et al. 2006; Peterson et al., 2009; Qin et al., 2010; Bianconi et al., 2013). These microbial communities are genetically diverse, varying considerably by individual, location in or on the body, host age, phase in life history, and by host species (Ley et al., 2008; Costello et al., 2009; Kim et al., 2009; Yildirim et al., 2010; Ravel et al., 2011; Aagaard et al., 2012; Faust et al., 2012; HMPC, 2012; Li et al., 2012; Yatsunenko et al., 2012; Stumpf et al., 2013; Swartz et al., 2014). Microbial communities also vary by host diet and habitat and are sensitive to alterations in the external environment (Amato et al., 2013; Gomez et al., 2015, 2016; Barelli et al., 2015).
Relationships between microbial communities and their primate hosts are critically important. Microbes profoundly affect primate health through interactions that range from commensal and mutualistic to pathogenic (Dethlefsen et al., 2006). In light of these interdependent relationships, host and their associated microbes are now considered more appropriately to be a 'supraorganism' or 'holobiont' (Rosenberg et al., 2010; Zilber-Rosenberg and Rosenberg, 2008; Singh et al., 2013), consisting of a single unit subject to evolutionary selection (Zilber-Rosenberg and Rosenberg, 2008; Yeoman et al., 2011).

We propose that microbial analyses offer valuable insight into primate health, nutrition, behavior, life history, and disease, with significant potential for informing primate conservation decisions. Recent advances in DNA sequencing now make it feasible and economically viable to conduct metagenomic analyses for assessing the community of microbes (bacteria, archaea, fungi, protists, and viruses) from a particular host or environment (Gill et al., 2006). By permitting rapid identification of microbial communities one can examine and compare microbiomes across a vast number of hosts, habitats, and species. Below, we suggest several ways in which the application of metagenomic analyses and a greater understanding of microbial ecology could contribute to effective conservation of primates and other taxa. We commence with an overview of the implications of the gut microbiome for host health and nutrition, and discuss the role of microbe-host interactions in a changing environment, in captive care, and in reintroductions. We also provide an overview of microbial applications for understanding host dispersal and conservation hotspots and investigate the potential of microbial phylogenetic analyses for understanding disease transmission and wildlife trafficking. Finally, we conclude with suggestions for future directions.

\subsection{Microbes and host health}

Primate hosts rely on microbes to conduct important metabolic and immune functions (Hooper et al., 2012; LeBlanc et al., 2013; Lee and Mazmanian, 2010; Lozupone et al., 2012; Tremaroli and Bäckhed, 2012; Yatsunenko et al., 2012). For example, much evidence supports the significant impact of the gastrointestinal GI tract microbiome on host health and nutrition (e.g., Ley et al., 2008; Muegge et al., 2011; Kau et al., 2011; Flint et al., 2012; Amato et al., 2013; Foster and McVey Neufeld, 2013; Gomez et al., 2015, 2016). Microbes conduct critical functions for the host by producing vitamins important for health and reproduction, (e.g., folate, B6, and B12 necessary for brain growth Moran et al., 2008), and synthesizing hormone-like molecules, which provide metabolic and reproductive regulation through modulation of signal transduction pathways, gene expression and splicing (Backhed et al., 2005; Blaser, 2006; Dethlefsen et al., 2007; Dominguez-Bello et al., 2010; Hehemann et al., 2010; Heijtz et al., 2011; Hooper et al., 2012; Mazmanian et al., 2008; Brownlie and Johnson, 2009; Costello et al., 2009; Round and Mazmanian, 2009).

Digestion and nutritional benefits, in particular, are strongly affected by the host microbiome (Stevens and Hume, 1998; Samuel et al., 2008; Sekirov et al., 2010; Grenham et al., 2011). For example, gut microbes in the large intestine play a significant role in increasing nutrient availability (Turnbaugh et al., 2006), largely by breaking down resistant fibers and starches, modulating nutrient absorption, and producing short chain fatty acids (SCFAs, e.g., acetate, propionate, and butyrate), an important source for host energy (Macfarlane and Macfarlane, 2003; Samuel et al., 2008). In humans, for example, SCFAs contributed by gut microbes provide $6-10 \%$ of the daily energy supply and nutrition (Stevens and Hume, 1998), whereas in more folivorous primates, such as gorilla, SCFAs produced by gut microbes during fermentation produce up to $57 \%$ of host daily energetic needs (Popovich et al., 1997).

In addition to augmenting host nutritional status, the microbiome is essential for host protection, contributing to the maturation and modulation of host immunity and barrier function by influencing innate and adaptive immune defenses (Rakoff-Nahoum et al., 2004; Bäckhed et al. 2004; Blaser, 2006; Dominguez-Bello et al., 2010; Dethlefsen 
et al., 2007; Mazmanian et al., 2008; Brownlie and Johnson, 2009; Costello et al., 2009; Round and Mazmanian, 2009; Ivanov et al., 2009; Lee and Mazmanian, 2010; Hooper et al., 2012; Schachtschneider et al., 2013). For example, experimental evidence indicates that germfree mice are characterized by an enlarged cecum, a reduced number and activity of Peyer's patches, smaller lymph nodes, and smaller intestine surface areas compared to conventional mice (Lee and Mazmanian, 2010). Without a microbiome, the gut-associated lymphoid tissue (GALT), which represents $70 \%$ of the immune system and is critical for host defense against GI pathogens, does not develop normally (Vaishnava et al., 2008; Hooper et al., 2012; Lopetuso et al., 2013). Microbes prevent pathogen colonization by competitive exclusion from attachment sites and receptors and via the production of anti-microbial compounds (Sekirov et al., 2010). Thus, microbes affect GI homeostasis, physiology, and immune function, and play fundamental roles in both preventing and causing disease. Variation in these microbial processes can directly affect host survival and reproduction (Dethlefsen et al., 2006; Lee and Mazmanian, 2010; Kau et al., 2011; Gogarten et al., 2012), underscoring their relevance to primate conservation.

\subsection{Microbial communities increase resource availability and buffer against food scarcity}

Microbial interactions in the gut are particularly important for primate hosts occupying stochastic or food-scarce habitats. GI microbes permit hosts to access energy sources and nutrients that would otherwise be unavailable (MacFarlane and MacFarlane, 2003; Samuel et al., 2008), a benefit that is particularly critical in a changing environment or one characterized by high seasonality and periodic reduced food availability. Moreover, evidence suggests that gut microbiome composition can change rapidly in response to host diet (David et al., 2014). Recent microbiome studies of wild gorillas and howler monkeys in habitats characterized as highly seasonal, with temporal restrictions on resource availability (e.g., alterations in fruit:fiber-rich food ratios) indicate that gut microbes impact nutritional efficiency (Gomez et al., 2015, 2016; Amato et al., 2015). Specifically, when relying on seasonally lower quality, more fibrous resources, gorilla and howler monkey gut microbes were instrumental in increasing the amount of energy obtained from these foods. Primates adjust to periods of low-quality food sources through an increased abundance of microbes able to metabolize resistant polysaccharides and produce energy-rich SCFA (Gomez et al. 2015, 2016; Amato et al., 2015). This suggests a role for microbes in buffering hosts during times of food scarcity or low quality diets. Thus, analyses of microbial community compositions may provide a direct method for monitoring primate health in unstable environments.

Evidence suggests that the microbiome may also buffer the host against food scarcity and environmental change by modulating fat storage (e.g. Faith et al., 2011; Turnbaugh et al., 2009; Williams et al., 2012; David et al., 2014). The microbiome and metabolome (the complete set of metabolites derived from host and bacterial metabolism) of wild gorillas consuming greater than average amounts of fruit exhibit profiles similar to those of humans and mice fed high fat, western-like diets. Specifically, they possess high levels of long chain fatty acids, high abundances of taxa related to Actinobacteria, and higher Firmicutes:Bacteroidetes ratios (Serino et al., 2012; Turnbaugh et al., 2009; Ley, 2010). These microbial characteristics associated with increased fat consumption and deposition may contribute to shortand long-term energy storage strategies that impact host fitness, allowing animals to cope with periods of energetic constraints.

These data support the hypothesis that the GI microbiota contributes significantly to the physiology, adaptability, and health of hosts and that these critical host-microbe interactions are responsive to environmental and dietary changes. Studies across broader comparative samples suggest that changes in the environment and host diet not only affect the host gut microbiome and digestive efficiency, but also immune and stress responses (Bauer et al., 2006; Turnbaugh et al., 2009;
Bailey, 2012; Hooper et al., 2012; David et al., 2014). As the global climate continues to change and primates experience more arid and seasonal environments, including more extreme fluctuations in temperatures, gut microbes may be increasingly important contributors to host foraging plasticity, efficiency, and ultimately resilience.

\subsection{Microbial communities reflect habitat degradation and stress}

Host-associated microbiomes are sensitive to environmental alterations and can thus be useful biomarkers for primate habitat quality, and in particular, health and diet. In a recent study of endangered black howler monkeys (Alouatta pigra) from the Chiapas, Mexico, Amato et al. (2013) found that the diversity and abundance of gut microbes varied considerably across populations, with an association between microbial operational taxonomic units (OTUs) and general habitat quality. Specifically, howler monkey populations inhabiting pristine continuous rainforest harbored significantly greater microbial richness and diversity compared to populations in forest fragments or captivity (Fig. 2). Similar findings were subsequently obtained for red colobus monkeys (Barelli et al., 2015). Additionally, howler monkeys in a fragmented evergreen rainforest had reduced relative abundances of butyrate-producing bacteria, butyrate being an important energy source and modulator of host health, and higher relative abundances of hydrogen-sulfide-producing bacteria, a class of organisms that carry out a potentially toxic form of hydrogenotrophy (Amato et al., 2013, 2014).

As habitat quality decreases, microbial diversity also decreases such that the captive howler populations contain a depauperate network of homogenous microbes lacking co-abundance networks (Fig. 3). These co-abundance relationships are thought to contain metabolic interdependencies, and thus increasing amodularity is associated with increased vulnerability of these complex communities (Yeoman et al., 2013; Lozupone et al., 2012). Moreover, diminishing habitats correspond to decreasing host population sizes and reduced host genetic diversity, which presumably also negatively affect microbiome diversity and richness. With fewer, more homogenous microbes, the chemical, genetic, and metabolic diversity of the microbiome is diminished. This in turn negatively impacts the nutritional value of the diet and benefit to the host. It is important to note that stable, healthy microbiomes also provide a protective function by preventing colonization by pathogenic microbes. Microbial dysbiosis can result in infection and disease arising not only from pathogenic microbes, but also from the absence of microbes or disruption of the commensal microbiome (Croswell et al., 2009; Dillon et al., 2005; Koch and Schmid-Hempel, 2011a, 2011b; Barelli et al., 2015).

Habitat degradation is associated with markers for host physiological and nutritional stress (Chapman et al., 2007; Rangel-Negrín et al., 2009;

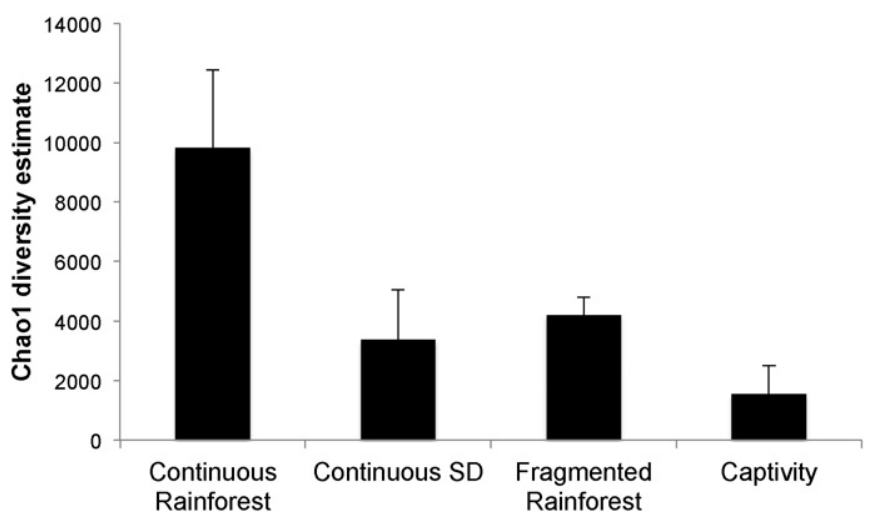

Fig. 2. Howler microbiomes clustered by host habitat. Bar graphs indicate the number of unique taxonomic units (sharing 97\% sequence identity) per total reads for each sample. Overall $=$ all populations, $\mathrm{CER}=$ Continuous Evergreen Rainforest; ER = Rainforest Fragment, SDR = Semi-deciduous Rainforest, Captive $=$ captive population. Analysis of variance of the log-linear regression coefficients confirmed habitat differences (F3, 31.28.91, $\mathrm{P}<0.0001$ ). Modified from Amato et al. (2013). 


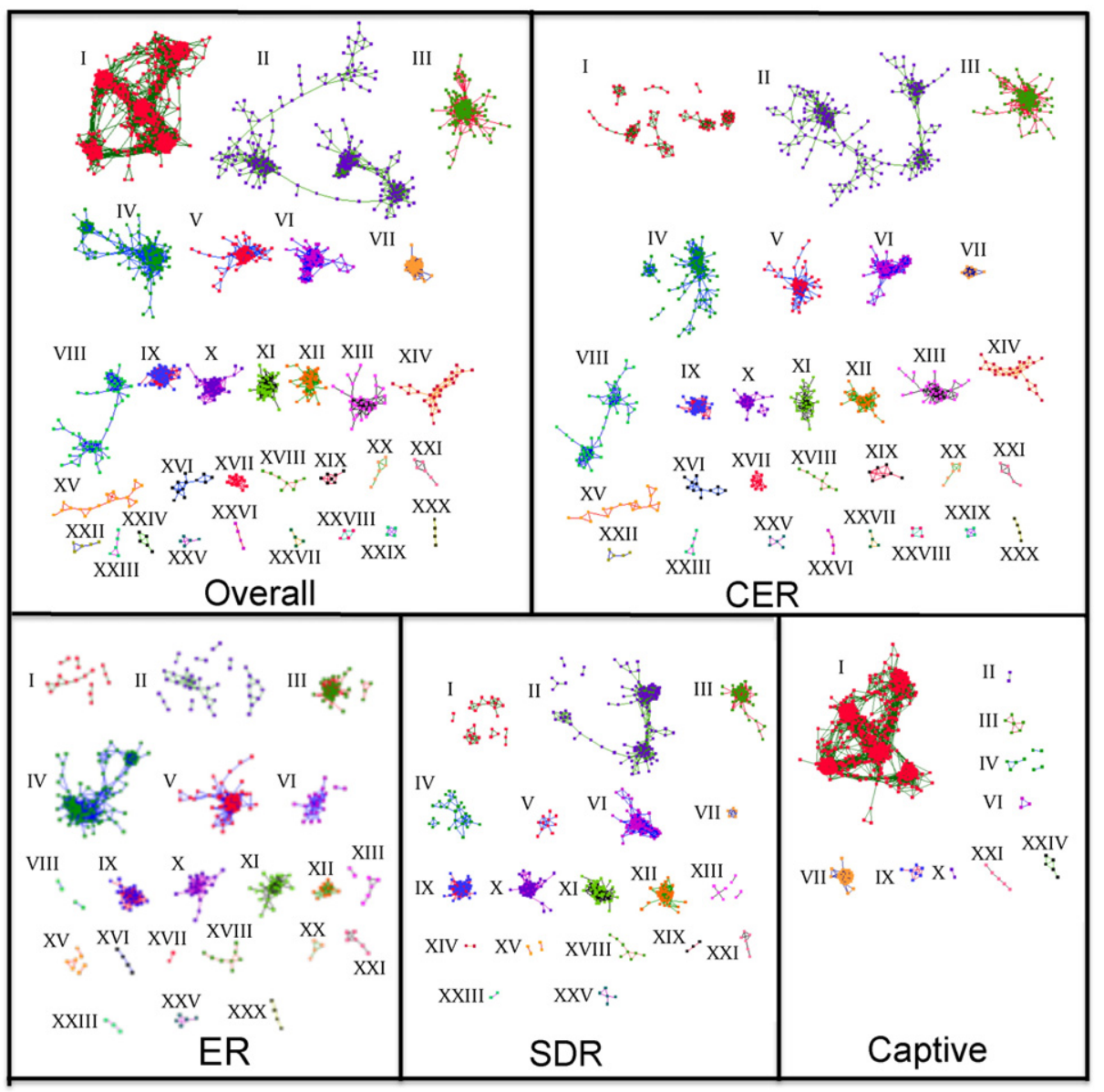

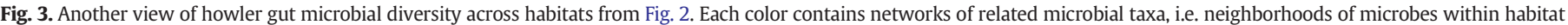

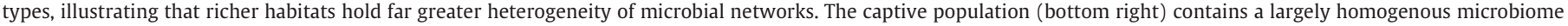
composed of closely related organisms in concentrated numbers (source: K. Amato, C. Yeoman).

Balestri et al., 2014). Studies of animal models demonstrate that the microbiome plays a major role in stressor-induced immunomodulation and that exposure to stressors changes the GI microbiome composition thereby increasing susceptibility to enteric pathogens and increasing innate immune activity (reviewed in Bailey 2012). In a study comparing four wild gorilla populations, Gomez et al. (2015; Fig. 4) found that GI microbiomes of a wild gorilla group under increased anthropogenic pressure could always be distinguished from that of all other groups by showing increased abundance of Fusobacteriaceae. High abundance of Fusobacteriaceae is associated with gut inflammation in humans and mice (Huycke and Gaskins, 2004; Castellarin et al., 2012). While the etiology of this microbial dysbiosis is still unclear, it appears to be associated with unfavorable diets and stress (Hawrelak and Myers, 2004). Gomez et al. (2015) cite higher incidences of human-derived enteric pathogens, stress-like behaviors, and altered feeding rates in the anthropogenicallydisturbed wild gorilla population (see also Klailova et al., 2010; Sak et al., 2013). Thus, host-associated microbiomes can serve a potential role as sentinels for habitat quality and stochastic changes in food availability. Shifts in GI microbiomes accompany increased stress or poor diet, they can also inform whether there are health issues related to habitat degradation, with direct implications for primate health and conservation.

1.4. Application of microbial analyses to improve health and survivorship in captivity, reintroductions and interventions

In response to habitat encroachment and plummeting populations, current conservation strategies include providing sanctuaries and increasing captive breeding. However, captivity represents an extreme version of environmental alteration and stress. Not surprisingly, captive breeding has had mixed success. For instance, captive but not wild marmosets and tamarins (Callidtrichidae) often succumb to chronic wasting syndrome (CWS), a syndrome ascribed to microbiial dysbiosis

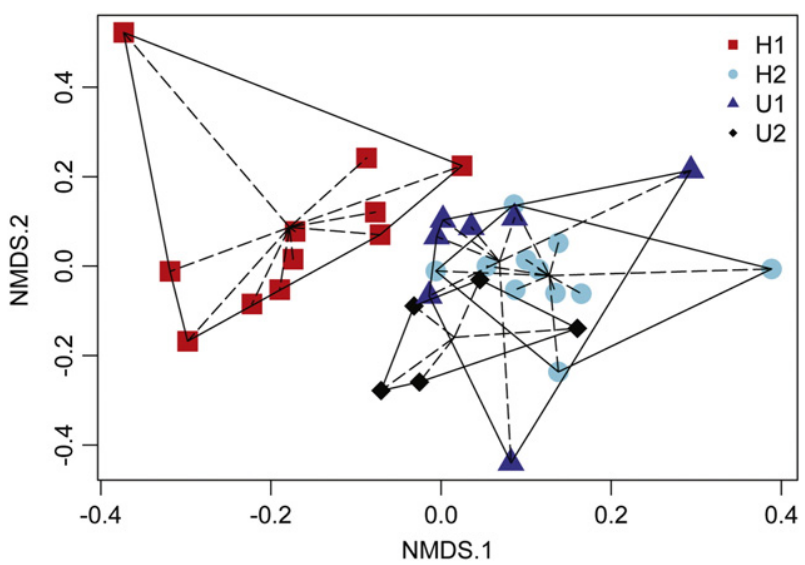

Fig. 4. Microbial community composition distances for four wild western Gorilla (G. g. gorilla) groups: H1: Habituated 1; H2: Habituated 2; U1 and U2: Unhabituated. The microbiome of habituated, H1, is different from that of any other group: H2, U1 and U2. Habituation of H1 started in 2000 and tourism began in September 2004, with an average frequency of 380 tourists per year during 2007-2009. H1 is the group under highest anthropogenic pressure. Habituation of $\mathrm{H} 2$ started in 2005, but tourism had not yet started at the time of sample collection (2009). Gomez et al. $(2015,2016)$. 
and characterized by diarrhea, loss of hair, paralysis of the hind limbs, and eventual mortality (Gore et al., 2001).

Notably, highly folivorous primates (e.g. Asian colobines, wooly spider monkeys) are particularly difficult to maintain in captivity (Janssen, 1994; Milton, 1986). Mortality rates are high and many succumb to diarrhea (Collins and Roberts, 1978; Oates and Davies, 1994; Pope, 1998). Specialized digestive systems of many folivorous primates consist of either a large multi-chambered stomach containing anaerobic cellulolytic bacteria that break down secondary toxins and foods with high cellulose content (Davies and Oates, 1994) or a large hindgut where microbial fermentation occurs within an enlarged cecum or colon (Chivers and Hladik, 1980). Considering the role of diet in shaping the GI microbiome, host-microbiome co-adaptation, and the critical role of the GI microbiome in processing hard-to-digest fiber and the toxins associated with a leafy diet, it is not surprising that captivity is also associated with a depauperate host GI microbiome and host morbidity (Amato et al., 2013; Kohl et al., 2014).

The challenge may lie in the inability of the captive environment to supply the specialized diets needed and meet the specific nutritional requirements due to lack of a diverse GI microbiome necessary to extract nutrients from their diet. Captive primates may also lack sufficient microbial and functional diversity necessary to obtain all the homeostatic compounds they rely upon from the food available in captive programs. Moreover, disruption of the complex fibrolytic bacterial communities of highly folivorous primates may diminish the ability to digest high-fiber diets effectively. In other folivorous mammals (e.g. equines), disruption of GI microbial content can have catastrophic consequences, including morbidity ( $\mathrm{Al}$ Jassim and Andrews, 2009). Microbiome monitoring has the potential to improve captive management by permitting rapid identification of shifts in GI microbial health and dysbiosis (Hale et al., 2015) and to aid in identifying the factors influencing diet-associated diseases associated with captivity (see also Less et al., 2014 for captive apes).

Microbial analyses also have the potential to improve the success rate of reintroduction efforts (e.g. Redford et al., 2012). Reintroductions have a notoriously poor success rate and are fraught with controversy (Stamps and Swaisgood, 2007). Unsuccessful reintroductions occur for multiple reasons including the animal's lack of experience or ability to survive in a natural environment, aggression from resident conspecifics, predation, disease, and other factors (Soorae, 2011). Evidence strongly suggests that releasing captive animals possessing relatively depauperate gut microbial communities (e.g. Amato et al., 2013) may further challenge survival during reintroductions. Given that sympatric hosts share microbial profiles (Goldberg et al., 2007, 2008; Moeller et al., 2013), reintroducing individuals with dysbiotic microbiomes may also negatively affect resident wild populations.

Applied and experimental research on captive and wild primate GI microbiomes (e.g. Nijboer et al., 2006; Kohl et al., 2014) are needed to test these hypotheses and to discern whether captive and reintroduced animals lack certain crucial microbes found in conspecifics in their introduced or native habitats. Microbiome analyses, monitoring, and treatments before, during, and after reintroductions may improve success rates. Strategies for improving the GI microbiome among captive and reintroduced individuals could include fecal transplantation or probiotic supplementations to enrich and 'normalize' the microbiome. Fecal microbiome transplantation from healthy individuals have demonstrated very high success rates for aiding recovery from disrupted GI microbial communities and re-establishing a normal gut microbiome among human hosts (Gough et al., 2011). Probiotics are also beginning to be utilized to combat maladies in other Orders, such as amphibians (e.g. Bletz, 2013). While more studies are needed to establish efficacy, applying microbial therapies to non-human primates (NHPs) has potential for re-establishing healthy microbiomes and decreasing morbidity and mortality rates. Conservation strategies that include consideration of microbiomes in the overall profile are also important for informing decisions to protect wild populations, particularly regarding the ethics and rationale for implementing certain types of interventions, such as antibiotic treatment (e.g., Warfield et al., 2014). While interventions may be helpful in stemming acute disease, unintended consequences may include negative effects on host GI microbiomes. For example, antibiotic use after serious respiratory disease outbreak in wild westernl lowland gorillas (G. g. gorilla) in Central African Republic was associated with decreased GI microbiome abundance and diversity (Vlčková et al., 2016). Controlled studies of the efficacy and safety of antibiotic use in primates and the development of best practices for intervention (potentially including concurrent probiotic treatments) are critically needed.

Microbiome analyses are increasingly being used to identify the microbial components (toxins and other virulence factors) that help to establish infection and cause disease, an important step toward the development of effective vaccines and treatments for NHPs, humans, and other taxa (e.g. Stanley et al., 2014; Mire et al., 2015; Ryan and Walsh, 2011, see also Rushmore et al., 2013) These same methods can also be used to identify individuals or populations containing particular disease-resistant microbes, which in turn could help prevent disease transmission to at-risk populations (e.g., Koch and Schmid-Hempel, 2011a, 2011b).

\subsection{Microbiomes can identify conservation hotspots and assess corridor effectiveness, dispersal and social networks}

Habitat loss and forest fragmentation are two of the main challenges to primate conservation (Cowlishaw and Dunbar, 2000; Estrada, 2013; Benchimol and Peres, 2014), resulting in declining primate populations, reduced densities and more restricted home ranges with limited dispersal opportunities, and leading to reduced genetic diversity and increased population vulnerability (Van Belle and Estrada, 2006; Boyle and Smith, 2010). Conservation biologists tasked with determining where to focus their limited resources and efforts face uncertain options with regard to these challenges. Rapid area assessments (RAPs) are often implemented to efficiently identify hotspots with high primate density and biomass for targeted conservation efforts. However, RAPs are often limited in their scope and duration (Stem et al., 2005) and difficult to monitor and evaluate (Rosenberg et al., 1997).

Another valuable conservation strategy involves establishing forest corridors interconnecting forest fragments. Corridors are touted to facilitate movement of wildlife among forest fragments, thereby promoting dispersal and exchange of genes among subpopulations with the goal of increasing effective population sizes (Rosenberg et al., 1997). However,

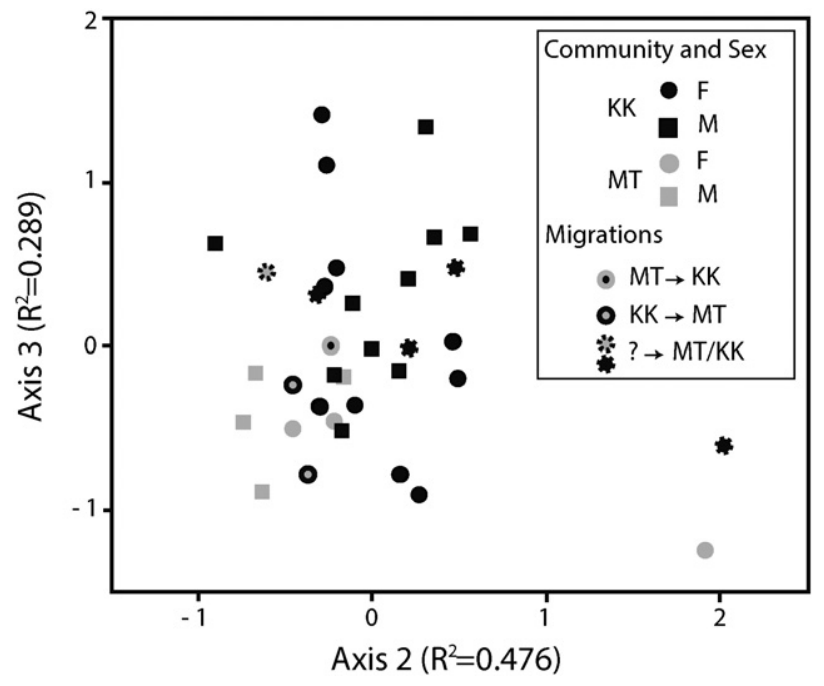

Fig. 5. Wild chimpanzee microbiomes are distinguished by host natal community affiliation. Individuals retain signatures of natal microbial communities even up to a decade after migration to new communities. Modified from Degnan et al. (2012). 
as with the identification of conservation hotspots, the effectiveness of corridors has been difficult to assess. To date, techniques to evaluate corridor usage and dispersal include mark-recaptures and gene flow. However, mark recapture is not effective for small population sizes (Mech and Hallett, 2001), and density, movement, and dispersal assessments are often based on inference and lack replication (Rosenberg et al., 1997), even when the target animals are well habituated and regularly followed (Stumpf et al., 2009). Assessing population gene flow requires large samples sizes that are challenging to obtain, and results are based on microsatellite loci distances between populations with inherent questions of validity, particularly in light of the unknown extent of admixture in populations and assumptions of similar divergence levels (e.g. Mech and Hallett, 2001). Consequently, identifying prime areas for corridor usage, gene exchange and ultimately protection is a major. But if it were possible to accurately identify regions of greatest emigration and immigration in a threatened population, then conservation efforts could be more effectively targeted.

Applying microbiome techniques to forest corridor and habitat assessments holds enormous promise for conservation. Recent microbiome analyses indicate that GI microbiomes reflect the biogeographical distribution of their primate hosts (Degnan et al. 2012; Moeller et al., 2013; Gomez et al., 2015, 2016; Tung et al., 2015; Fig. 5). Specifically, GI microbiomes of conspecifics can be differentiated by location of origin and by community affiliation. In a recent study, wild gorilla groups occupying different geographical ranges were characterized by differential abundances of metabolites and bacterial taxa associated with the metabolism of cellulose, phenolics, organic acids, simple sugars, lipids and sterols (Gomez et al., 2015, 2016). Moreover, microbial biogeographic signatures may persist for up to a decade, allowing primate natal community members to be identified many years after dispersal (Degnan et al., 2012; Moeller et al., 2013; see also Faith et al., 2013).

Human and NHPs carry unique microbial 'fingerprints' that are stable over time (Fierer et al., 2010; Franzosa et al., 2015; Nguyen et al., in review). Applying these findings to conservation efforts, fecal microbiome analyses from a targeted habitat, combined with information about the life history and social structure of the host, would permit identification of the natal community of origin for each individual, which in turn could shed light on dispersal patterns and facilitate the mapping of home ranges for discrete primate communities (see also Phillips et al., 2012). Results indicating a diversity of microbial signatures for a population in a particular habitat support that the range or forest corridor is a major area for gene flow, and therefore a conservation hotspot. In contrast, microbial signatures that are homogenous and/or depauperate, imply a population at risk of isolation. In such cases conservation strategies could focus on increasing interconnection between habitats and species. Following establishment of such connections, the populations could be monitored using metagenomics over time to determine whether the corridors are being used effectively to stabilize the population.

Microbiome studies are also contributing to our understanding of primate sociality (Archie and Theis, 2011) and social networks (Tung et al., 2015) relevant with regard to a species' natural history and for mapping potential disease connectivity (e.g., Rushmore et al., 2013). Thus, microbiome biogeographic signatures provide a means to assess primate densities, regions of maximum dispersal and conspecific interchange, social networks, and to model disease spread, all of which have valuable implications for improving conservation outcomes.

1.6. Microbial phylogenies as forensic tools for identifying diseases, transmission pathways, and wildlife trafficking

Pathogenic microbes, including viruses, bacteria, parasites, and fungi have major impacts on host health (Bermejo et al., 2006; Boesch, 2008; Goldberg et al., 2007, Rwego et al., 2008; Kondgen et al., 2008; Williams et al., 2008). Transmission can be eipzootic (transmitted among

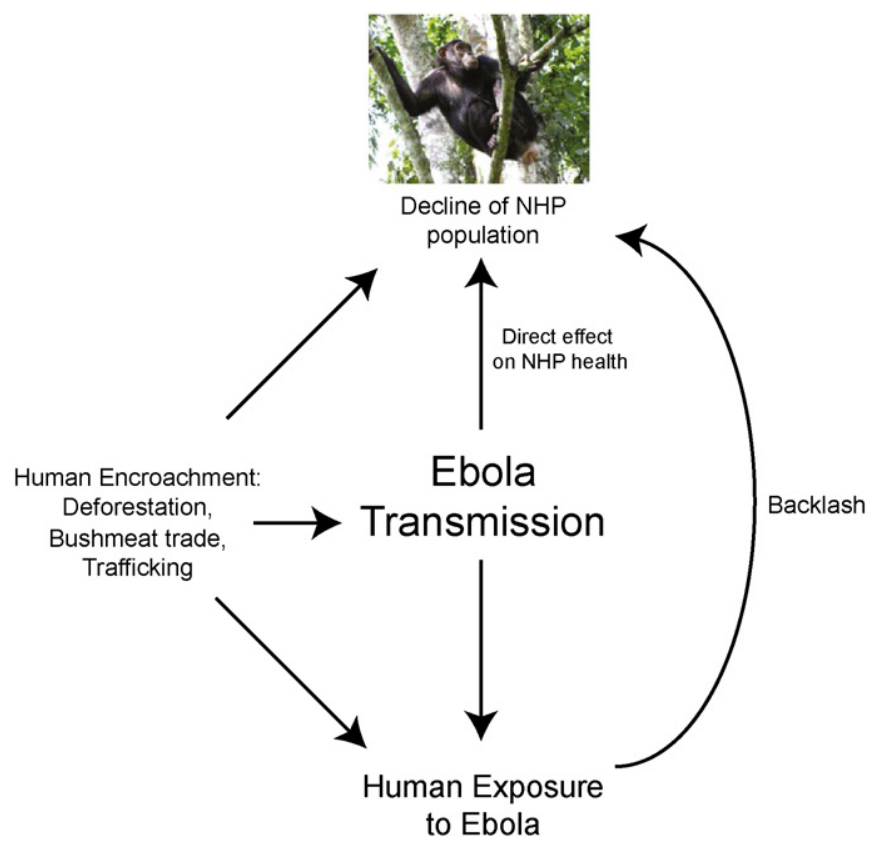

Fig. 6. Ebola is a conservation issue. Ebola has decimated non-human primate (NHP) populations. Human-mediated deforestation, bushmeat hunting, and wildlife trafficking diminish NHP populations while simultaneously increasing human exposure to Ebola. NHPs also suffer from backlash as they are often implicated as the source of Ebola.

animals), zoonotic (transmitted from animals to humans; e.g., Le Guenno et al., 1995; Formenty et al., 1999) or anthroponotic (transmitted from humans to other species; e.g., Bermejo et al., 2006; Chi et al., 2007; Kondgen et al., 2008). Growing interactions between wildlife and humans are exponentially increasing, raising the risks and likelihood for increased disease transmission. Indeed, $70 \%$ of all emerging infectious diseases in humans are zoonotic in nature (Taylor et al., 2001). For instance, compelling evidence implicates wild NHPs as an active reservoir for Treponema pallidum, the infectious agent of yaws and syphilis (Harper et al., 2012; Zobaníková et al., 2013). We propose that phylogenetic analyses of pathogenic microbes (viral, bacterial, fungal, or parasitic) offer a critical tool for preventing future outbreaks and diminishing their effects on primates (including humans).

The Ebola virus is one recent example of the multifaceted impacts driven by disease outbreaks, on both human and NHPs. The emergence and impact of Ebola cannot be understood or mitigated without recognizing the impact of the virus on NHPs. A number of factors contributing to viral-host interactions are affected by humanNHP interactions, such as the role of deforestation, bushmeat trafficking, and backlash by humans against perceived viral hosts. Within this framework, there is a key role for phylogenetic analyses of the pathogenic microbes for conservation and disease prevention (Fig. 6).

The Ebola virus first emerged in equatorial Africa in 1976 (Walsh et al., 2005). The first Ebola strain, Zaire ebolavirus (ZEBOV), was responsible for hundreds of human deaths in Congo. Since then, multiple outbreaks have occurred across equatorial Africa with different virulence and human mortality rates. Commencing in 2014, the world experienced the largest outbreak of Ebola to date, with $>99 \%$ of the current cases occurring in West Africa. As of April 2015, over 11,308 people had died from this outbreak and over 28,600 cases were reported (WHO) (Fig. 7). This episode crossed more borders than any prior outbreak and expanded internationally, leading to a global public health crisis. 


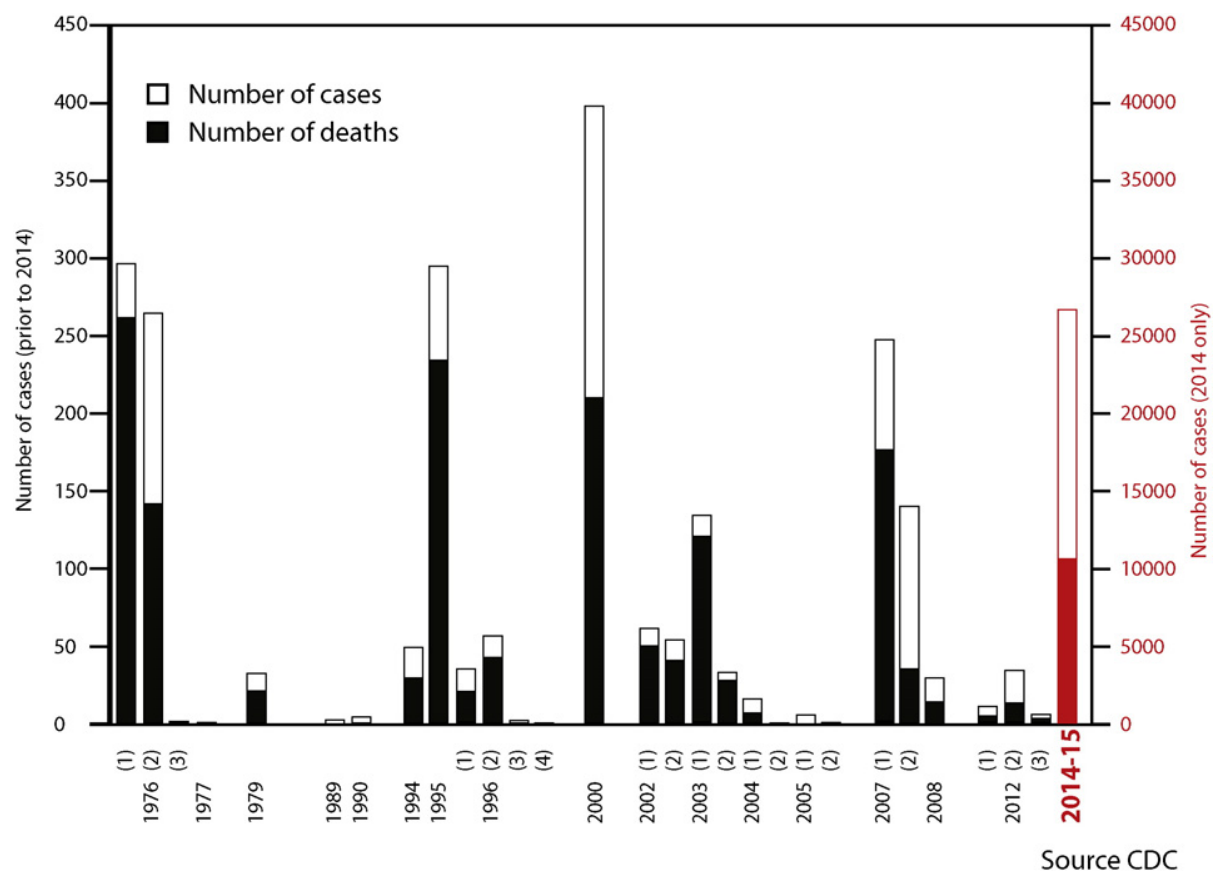

Fig. 7. Magnitude and mortality of Ebola outbreaks since 1976. Data from CDC.

In addition to the human tragedy of Ebola, this disease decimated NHP populations (Walsh et al., 2003; Ryan and Walsh, 2011). In the last 15 years, Ebola has killed one-third of Western lowland gorillas (Gorilla gorilla) throughout their range (Leroy et al., 2004; Bermejo et al., 2006). The Ebola strain discovered in 1993 in the Ivory Coast was transmitted directly from an infected chimpanzee (Pan troglodytes verus) (Le Guenno et al., 1995; Formenty et al., 1999). 12.9\% of wild chimpanzees (Pan troglodytes troglodytes) in Cameroon, Gabon and Congo possess antibodies to Ebola (Leroy et al., 2004), indicating that these ape populations have also been greatly affected by the disease.

Deforestation and human encroachment into wild habitats are inextricably tied to zoonotic transmission. The past 40 years have seen largescale habitat destruction. For example, over $50 \%$ of Liberian forests have been sold to industrial loggers (Karsenty, 2007). Sierra Leone retains less than $4 \%$ of its once widespread forest (IUCN, 1993). Habitat destruction and encroachment from logging, new roads, and increasing land use for agriculture simultaneously decimate wildlife populations and result in increasing contact between NHPs, humans, and domestic animals, all of which enhance the potential for zoonotic transmission (Jones et al., 2008; Gillespie et al., 2008; Wood et al., 2012). Mining, trafficking, and demand for bushmeat likewise degrade primate habitat and

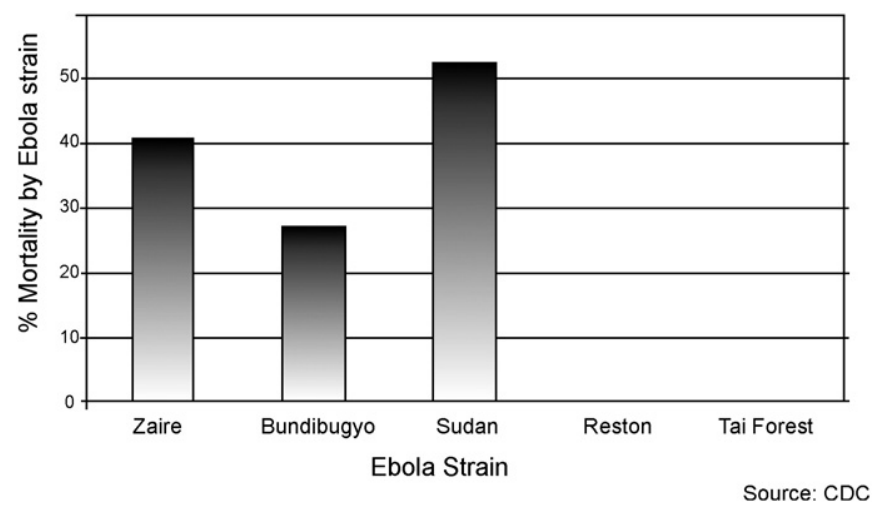

Fig. 8. Variation in mortality rates of different Ebola strains. Data from CDC. populations while exacerbating human-wildlife contact and conflict (Walsh et al., 2003). Ebola and other filovirus outbreaks have occurred in several African ape range states, including Angola, the Democratic

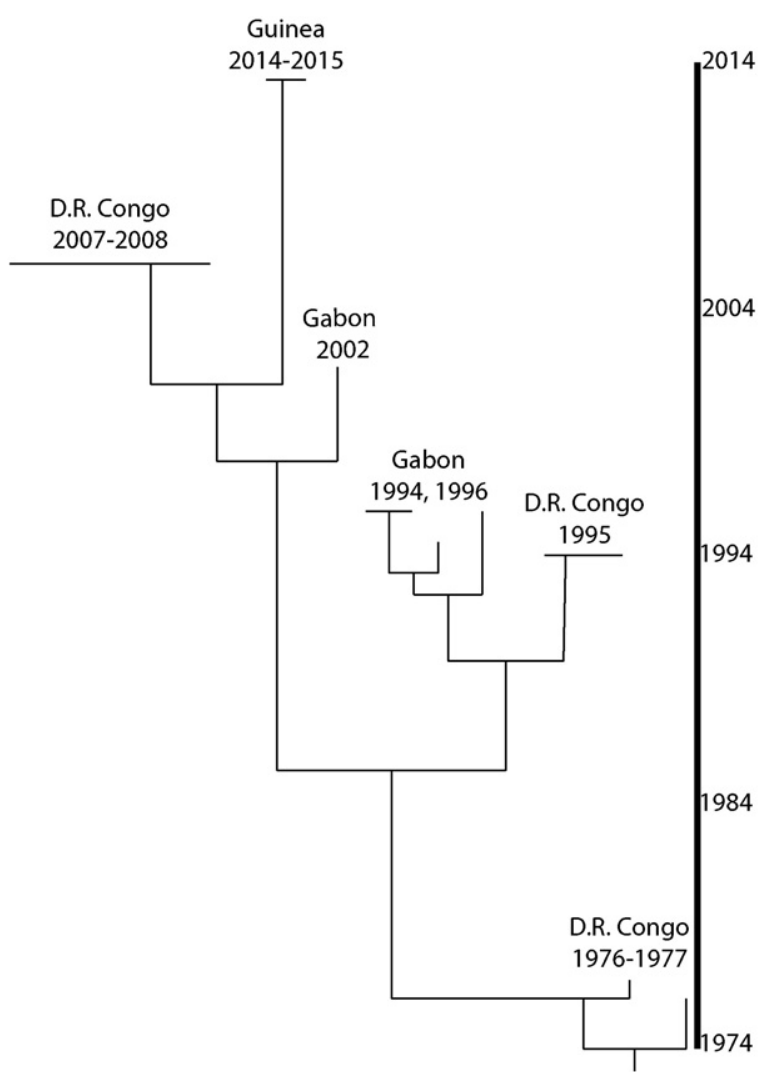

Adapted from Calvignac Spencer et al. (2014) PLOS Current Outbreaks

Fig. 9. Phylogeny of Ebola outbreaks scaled chronologically. The Guinean outbreak is most similar to Ebola from Congo. Animal trafficking may be implicated in the spread of the virus from Congo to Guinea. Data from Calvignac-Spencer et al. (2014). 
Republic of Congo, and Uganda. The 2007 outbreak of Ebola in Bundibugyo occurred close to several chimpanzee populations: Semliki National Park Rwenzori National Park, Toro Game Reserve, and Kibale National Park (Ryan and Walsh, 2011). In such cases, human Ebola outbreaks follow wildlife mortality (Rouquet et al., 2005). Habitat conservation and protection are critical for preventing future outbreaks.

Phylogenetic analyses of pathogenic microbes using metagenomic and next-generation DNA sequencing offer powerful, underutilized forensic and epidemiological tools for examining disease origins and evolutionary relationships in order to identify transmission pathways and mitigate the factors affecting disease transmission. For example, phylogenetic analyses indicate that the Ebola strain implicated in the recent West African Ebola (Guinea 2014 EBOV) is wholly distinct from the previous West African (Taï Forest) strain (Calvignac-Spencer et al., 2014; Dudas and Rambaut, 2014: Fig. 8) and is most closely related to the more deadly Zairian strain (ZEBOV) centered in present day Congo (Fig. 9; Calvignac-Spencer et al., 2014; Dudas and Rambaut, 2014). Thus, Guinea 2014 EBOV is argued to be most likely the result of a fairly recent introduction of ZEBOV from Central Africa rather than a long-term endemic West African strain (Calvignac-Spencer et al., 2014; Dudas and Rambaut, 2014).

How this strain arose in West Africa is central for understanding and preventing transmission. Bats or another unknown reservoir may have carried the strain from Congo. However the distances between outbreak sites are sizeable, particularly for a bat vector, and if Congo were the source, then presumably, the disease would have occurred earlier in areas near Congo and spread outward from there, rather than punctuated spread jumping across to West Africa. Human transmission is another possibility, but again, this appears less likely in the absence of gradual spread outward from Congo. Moreover, no adults were implicated in this outbreak and the first reported case in Guinea occurred in a small child. One proposed scenario is that the virus was transported via the bushmeat trade from Congo to Guinea (Stiles, 2014). Ten western gorillas (Gorilla gorilla) were exported from Guinea to China in 2010, and Congolese bonobos (Pan paniscus) were recently exported from Guinea to Armenia, suggesting that this is an active route for wildlife trafficking (Stiles, 2014). Such trafficking could account for the rapid jump of this strain from Congo to Guinea without affecting the human populations in between. Progress on mitigating the impact of Ebola on public health is inextricably tied to ongoing conservation efforts, and microbial analyses offer an important diagnostic tool for such efforts.

Beyond the Ebola viral outbreak, microbial phylogenetic analyses have been effective for identifying routes of transmission for other microbial pathogens from wildlife to humans (e.g. Taylor et al., 2001, see also Gao et al., 1999; Pedersen et al., 2005; Keele et al., 2006), as well as the transmission of microbial pathogens from humans to wildlife. For example, phylogenetic analyses reveal that disease outbreaks that killed chimpanzees and gorillas share a close phylogenetic relationship with human viruses (Leendertz et al. 2004, 2006; Bermejo et al., 2006; Chi et al., 2007; Kondgen et al., 2008; Lonsdorf et al., 2006; Williams et al., 2008; Boesch, 2008; Palacios et al., 2011; Ryan and Walsh, 2011). Humans are presumed to be responsible for additional outbreaks among other primates (e.g. yellow fever in howler monkeys: Bicca-Marques and Santos de Freitas, 2010; Holzmann et al., 2010; Almeida et al., 2012) and non-primates (e.g. Laurenson et al., 1998; Daszak et al., 2000). As metagenomic and phylogenetic analyses become more economical, informative, and accurate, their importance for conservation will continue to increase.

Increased fear toward NHP populations is a growing concern, and preventing a backlash directed at NHPs requires a different level of intervention. For instance, the main route of Ebola transmission to humans is thought to be cross-species contact (Taylor et al. 2001, see also Laurenson et al., 1998; Gao et al., 1999; Daszak et al., 2000; Pedersen et al., 2005; Keele et al., 2006). NHPs can be mistakenly inferred as the vector of the pathogens themselves, particularly with health department posters graphically illustrating diseases spread from NHPs to humans. Disease surveillance programs that apply rapid analyses to identify local disease reservoirs and monitor infection and spread can also aid conservation efforts by clearing nearby wildlife of suspicion, thus helping to prevent backlash, a very real detriment to primate populations. Microbial analyses targeting important sentinels can serve to aid health assessments in host communities (Calvignac-Spencer et al., 2012). For example, researchers recently detected a novel virus (ChiSCV) in stool samples collected from one wild chimpanzee community, suggesting that something particular to that environment was infecting individuals and spreading (Blinkova et al., 2010). Lastly, mounting evidence indicates that individuals carry unique microbial signatures that could be used as individual as well as population identifiers (e.g. Fierer et al., 2010; Nguyen et al., in review). These findings hold potential for combatting wildlife trafficking, currently an exceedingly difficult task. However, microbial surveillance could eventually be applied to identify the biogeographic origins of confiscated wildlife and thus target and protect source populations that are vulnerable to trafficking.

\section{Conclusions and future directions}

Clearly, microbial communities are diverse and dynamic, varying extensively by location, within and between individuals, and by host species. Microbial communities are closely linked to host health and monitoring their community structure and stability can aid primate welfare in the wild and in captivity. Microbes enable extraction of additional resources from host diets, and can be used to buffer hosts against food scarcity and poor nutritional quality. Understanding host microbial function can support the health of captive populations and interventions may aid primate health during reintroduction programs. Phylogenetic profiles of the microbes implicated in disease outbreaks can be used as signatures of primate trafficking and disease origin and transmission. Microbial analyses offer ways of monitoring primate population health, density, movement, and dispersal, and can be used to evaluate the efficacy of conservation strategies. Thus, microbiome analyses offer a non-invasive window into host health, nutrition, distribution, and disease with important implications for conservation.

Despite of their vast potential, microbial analyses are underutilized for conservation applications. To date, no conservation policy or legislation includes microbiome assessments. Fortunately, next generation DNA sequencing is now an economically viable approach, such that microbial analyses can be effectively and accurately integrated into conservation strategies. These methods and strategies could be applied to a broad range of wildlife, and the rapidly growing technological advances in portable sequencing machines will greatly facilitate field data collection. Future directions for microbiome applications that enable more focused conservation efforts include recognizing early signs of impending microbial dysbiosis, understanding how gut microbes buffer against nutritional challenges in susceptible ecosystems, targeting geographic regions as conservation priorities, providing a mechanism for understanding population declines, decreasing the risks while increasing the efficacy of interventions for improving host health, and identifying major hotspots and forest corridors for emigration. The recent Ebola outbreak highlights the importance of rapid, accurate assessments of microbial ecosystem diversity and function, the factors affecting microbiome variation and disease transmission, and host-microbiome responses to human impact and habitat degradation. While most host-microbiome studies focus on bacteria and viruses, the rise in fungal epidemics among bats, amphibians, and other organisms (Fisher et al., 2012) provide another critical application for microbial monitoring, disease prevention, and conservation. The application of microbial ecology and metagenomic analyses to conservation is currently in its infancy, but understanding the patterns of and factors affecting microbial diversity holds vast potential for preserving primate (including 
human) health and broader biodiversity and for informing conservation strategies worldwide.

\section{Acknowledgements}

We wish to thank S. Yildirim, S. Thomas, J. Umana, A. Rivera, J. Rushmore, A. Estrada, K. Petrzelkova, K. Vlčková, K. Langergraber, F. Teodoro, S. Sanford, L. McElheny, N. Nguyen, D. Wood, P. Jamieson, C. Grossman, C. Yao, A. Ford, A. Serlin, N. Murray, D Corbitt, and A. Asangba. We also acknowledge support from the UIUC Keck Center, J. Craig Ventner Institute, the University of Illinois, the J.S. Guggenheim Foundation, the C.R Woese Institute for Genomic Biology, the University of Colorado, NSF BCS 0935374, NSF BCS 0820709, and NSF BCS 1441409 .

\section{References}

Aagaard, K., Riehle, K., Ma, J., Segata, N., Mistretta, T.A., Coarfa, C., Raza, S., Rosenbaum, S. Van den Veyver, I., Milosavlijevic, A., et al., 2012. A metagenomic approach to characterization of the vaginal microbiome signature in pregnancy. PLoS One 7 (6), e36466. http:// dx.doi.org/10.1371/journal.pone.0036466.

Al Jassim, R.A., Andrews, F.M., 2009. The bacterial community of the horse gastrointestinal tract and its relation to fermentative acidosis, laminitis, colic, and stomach ulcers. Vet Clin. North Am. Equine Pract. 25, 199-215.

Almeida, M.A.B.D., Santos, E.D., Cardoso, J.D.C., Fonseca, D.F.D., Noll, C.A., Silveira, V.R., Maeda, A.Y., Souza, R.P.D., Kanamura, C., Brasil, R.A., 2012. Yellow fever outbreak affecting Alouatta populations in southern Brazil (Rio Grande do Sul State), 20082009. Am. J. Primatol. 74 (1), 68-76.

Amato, K.R., Leigh, S.R., Kent, A., Mackie, R.I., Yeoman, C.J., Stumpf, R.M., Wilson, B.A., Nelson, K.E., White, B.A., Garber, P.A., et al., 2015. The gut microbiota appears to compensate for seasonal diet variation in the wild black howler monkey. Microb. Ecol. 69 (2), 434-443.

Amato, K.R., Yeoman, C.J., Kent, A., Carbonero, F., Righini, N., Estrada, A.E., Gaskins, H.R., Stumpf, R.M., Yildirim, S., Torralba, M., et al., 2013. Habitat degradation impacts black howler monkey (Alouatta pigra) gastrointestinal microbiomes. Int. Soc. Microb. Ecol. J. 7, 1344-1353.

Archie, E.A., Theis, K.R., 2011. Animal behaviour meets microbial ecology. Anim. Behav. 82, 425-436.

Backhed, F., Ley, R.E., Sonnenburg, J.L., Peterson, D.A., Gordon, J.I., 2005. Host-bacterial mutualism in the human intestine. Science 307, 1915-1920.

Bäckhed, F., Ding, H., Wang, T., Hooper, L.V., Koh, G.Y., Nagy, A., ... Gordon, J.I., 2004. The gut microbiota as an environmental factor that regulates fat storage. Proc. Natl. Acad. Sci. U. S. A. 101 (44), 15718-15723.

Bailey, M.T., 2012. The contributing role of the intestinal microbiota in stressor-induced increases in susceptibility to enteric infection and systemic immunomodulation. Horm. Behav. 62, 286-294.

Balestri, M., Barresi, M., Campera, M., Serra, V., Ramanamanjato, J.B., Heistermann, M., et al., 2014. Habitat degradation and seasonality affect physiological stress levels of Eulemur collaris in littoral forest fragments. PLoS One 9 (9), e107698.

Barelli, C., Albanese, D., Donati, C., Pindo, M., Dallago, C., Rovero, F., Cavalieri, D., Tuohy, K.M., Hauffe, H.C., De Filippo, C., 2015. Habitat fragmentation is associated with gut microbiota diversity of an endangered primate: implications for conservation. Sci. Rep. 5, 14862. http://dx.doi.org/10.1038/srep14862.

Bauer, E., Williams, B.A., Smidt, H., Verstegen, M.W., Mosenthin, R., 2006. Influence of the gastrointestinal microbiota on development of the immune system in young animals. Curr. Issues Intest. Microbiol. 7, 35-52.

Benchimol, M., Peres, C.A., 2014. Predicting primate local extinctions within "real-world" forest fragments: a pan-neotropical analysis. Am. J. Primatol. 76, 289-302.

Bermejo, M., Rodriguez-Teijeiro, J.D., Illera, G., Barroso, A., Vila, C., et al., 2006. Ebola outbreak killed 5000 gorillas. Science 314, 1564

Bianconi, E., Piovesan, A., Facchin, F., Beraudi, A., Casadei, R., Frabetti, F., Vitale, L., Pelleri, M.C., Tassani, S., Piva, F., et al., 2013. Ann. Hum. Biol. 40, 463-471.

Bicca-Marques, J.C., de Freitas, D.S., 2010. The role of monkeys, mosquitoes, and humans in the occurrence of a yellow fever outbreak in a fragmented landscape in south Brazil: protecting howler monkeys is a matter of public health. Tropic. Conserv. Sci. 3 (1).

Blaser, M., 2006. Who are we? Indigenous microbes and the ecology of human diseases. Eur. Mol. Biol. Organ. Rep. 7, 956-960.

Bletz, M.C., 2013. Mitigating amphibian chytridiomycosis with bioaugmentation: characteristics of effective probiotics and strategies for their selection and use. Ecol. Lett. 16, 807-820.

Blinkova, O., Victoria, J., Li, Y., Keele, B.F., Sanz, C., Ndjango, J.B., Peeters, M., Travis, D., Lonsdorf, E.V., Wilson, M.L., et al., 2010. Novel circular DNA viruses in stool samples of wild-living chimpanzees. J. Gen. Virol. 91 (Pt 1), 74-86.

Boesch, C., 2008. Why do chimpanzees die in the forest? The challenges of understanding and controlling for wild ape health. Am. J. Primatol. 70, 722-726.

Boyle, S.A., Smith, A.T., 2010. Can landscape and species characteristics predict primate presence in forest fragments in the Brazilian Amazon? Biol. Conserv. 143 (5), 1134-1143.

Brownlie, J.C., Johnson, K.N., 2009. Symbiont-mediated protection in insect hosts. Trends Microbiol. 17, 348-354.

Calvignac-Spencer, S., Leendertz, S.A., Gillespie, T.R., Leendertz, F.H., 2012. Wild great apes as sentinels and sources of infectious disease. Clin. Microbiol. Infect. 18, 521-527.
Calvignac-Spencer, S., Schulze, J.M., Zickmann, F., Renard, B.Y., 2014. Clock rooting further demonstrates that Guinea 2014 EBOV is a member of the Zaïre lineage. PLoS Curr. Outbreaks 6. http://dx.doi.org/10.1371/currents.outbreaks.c0e035c86d721668a6ad73 53f7f6fe86 (ecurrents.outbreaks.c0e035c86d721668a6ad7353f7f6fe86).

Castellarin, M., Warren, R.L., Freeman, J.D., Dreolini, L., Krzywinski, M., Strauss, J., Barnes, R. Watson, P., Allen-Vercoe, E., Moore, R.A., Holt, R.A., 2012. Fusobacterium nucleatum infection is prevalent in human colorectal carcinoma. Genome Res. 22 (2), 299-306.

Chapman, C.A., Saj, T., Snaith, T.V., 2007. Temporal dynamics of nutrition, parasitism and stress in colobus monkeys: implications for population regulation and conservation. Am. J. Phys. Anthropol. 134, 240-250.

Chi, F., Leider, M., Leendertz, F., Bergmann, C., Boesch, C., Schenk, S., Pauli, G., Ellerbrok, H. Hakenbeck, R., 2007. New Streptococcus pneumoniae clones in deceased wild chimpanzees. J. Bacteriol. 189 (16), 6085-6088.

Chivers, D.J., Hladik, C.M., 1980. Morphology of the gastrointestinal tract in primates: comparisons with other mammals in relation to diet. J. Morphol. 166, 337-386.

Collins, L., Roberts, M., 1978. Arboreal folivores in captivity-maintenance of a delicate minority. In: Montgomery, G.G. (Ed.), Ecology of Arboreal Folivores. Smithsonian Institution Press, Washington, DC.

Costello, E.K., Lauber, C.L., Hamady, M., Fierer, N., Gordon, J.I., Knight, R., 2009. Bacterial community variation in human body habitats across space and time. Science 326, 1694-1697.

Cowlishaw, G., Dunbar, R., 2000. Primate Conservation Biology. University of Chicago Press, Chicago.

Croswell, A., Amir, E., Teggatz, P., Barman, M., Salzman, N.H., 2009. Prolonged impact of antibiotics on intestinal microbial ecology and susceptibility to enteric Salmonella infection. Am. Soc. Microbiol. 77, 2741-2753.

Daszak, P., Cunningham, A.A., Hyatt, A.D., 2000. Emerging infectious diseases of wildlifethreats to biodiversity and human health. Science 287 (5452), 443-449.

David, L.A., Maurice, C.F., Carmody, R.N., Gootenberg, D.B., Button, J.E., Wolfe, B.E., Ling, A.V., Devlin, A.S., Varma, Y., Fischbach, M.A., et al., 2014. Diet rapidly and reproducibly alters the human gut microbiome. Nature 505, 559-563.

Davies, G., Oates, J.F. (Eds.), 1994. Colobine Monkeys: Their Ecology, Behaviour and Evolution. Cambridge University Press, Cambridge. UK.

Degnan, P.H., Pusey, A.E., Lonsdorf, E.V., Goodall, J., Wroblewski, E.E., Wilson, M.L., Rudicell, R., Hahn, B.H., Ochman, H., 2012. Factors associated with the diversification of the gut microbial communities within chimpanzees from Gombe National Park. Proc. Natl. Acad. Sci. U. S. A. 109, 13034-13039.

Dethlefsen, L., Eckburg, P.B., Bik, E.M., Relman, D.A., 2006. Assembly of the human intestinal microbiota. Trends Ecol. Evol. 21, 517-523.

Dethlefsen, L., McFall-Ngai, M., Relman, D.A., 2007. An ecological and evolutionary perspective on human-microbe mutualism and disease. Nature 449, 811-818.

Dillon, R.J., Vennard, C.T., Buckling, A., Charnley, A.K., 2005. Diversity of locust gut bacteria protects against pathogen invasion. Ecol. Lett. 8, 1291-1298.

Dominguez-Bello, M.G., Costello, E.K., Contreras, M., Magris, M., Hidalgo, G., Fierer, N. Knight, R., 2010. Delivery mode shapes the acquisition and structure of the initial microbiota across multiple body habitats in newborns. Proc. Natl. Acad. Sci. 107, 11971-11975.

Dudas, G., Rambaut, A., 2014. Phylogenetic analysis of Guinea 2014 EBOV Ebolavirus outbreak. PLoS Curr. Outbreaks 6.

Estrada, A., 2013. Socioeconomic contexts of primate conservation: population, poverty, global economic demands and sustainable land use. Am. J. Primatol. 75, 30-45.

Faith, J.J., McNulty, N.P., Rey, F.E., Gordon, J.I., 2011. Predicting a human gut microbiota's response to diet in gnotobiotic mice. Science 333, 101-104.

Faith, J.J., Guruge, J.L., Charbonneau, M., Subramanian, S., Seedorf, H., Goodman, A.L. Clemente, J.C., Knight, R., Heath, A.C., Leibel, R.L., Rosenbaum, M., 2013. The longterm stability of the human gut microbiota. Science 341, 1237439.

Faust, K., Sathirapongsasuti, J.F., Izard, J., Segata, N., Gevers, D., Raes, J., Huttenhower, C., 2012. Microbial co-occurrence relationships in the human microbiome. PLoS Comput. Biol. 8 (7), e1002606.

Fierer, N., Lauber, C.L., Zhou, N., McDonald, D., Costello, E.K., Knight, R., 2010. Forensic identification using skin bacterial communities. Proc. Natl. Acad. Sci. 107 (14), 6477-6481.

Fisher, M.C., Henk, D.A., Briggs, C.J., Brownstein, J.S., Madoff, L.C., McCraw, S.L., Gurr, S.J., 2012 Emerging fungal threats to animal, plant and ecosystem health. Nature 484, 186-194.

Flint, H., Scott, K., Louis, P., Duncan, S., 2012. The role of the gut microbiota in nutrition and health. Nat. Rev. Gastroenterol. Hepatol. 9, 577-589.

Formenty, P., Boesch, C., Wyers, M., Steiner, C., Donati, F., Dind, F., Walker, F., Le Guenno, B., 1999. Ebola virus outbreak among wild chimpanzees living in a rain forest of Côte d'Ivoire. J. Infect. Dis. 179 (Supplement 1), S120-S126.

Foster, J.A., McVey Neufeld, K.A., 2013. Gut-brain axis: how the microbiome influences anxiety and depression. Trends Neurosci. 36, 305-312.

Franzosa, E., Huang, K., Meadow, J.F., Gevers, D., Lemon, K.P., Bohannan, B., Huttenhower, C., 2015. Identifying personal microbiomes using metagenomics codes. Proc. Natl. Acad. Sci. e2930-e2938.

Gao, H., Huang, Y., Nix, W.D., 1999. Modeling plasticity at the micrometer scale Naturwissenschaften 86, 507-515.

Gill, S.R., Pop, M., DeBoy, R.T., Eckburg, P.B., Turnbaugh, P.J., Samuel, B.S., ... Nelson, K.E., 2006. Metagenomic analysis of the human distal gut microbiome. Science 312 (5778), 1355-1359.

Gillespie, T.R., Nunn, C.L., Leendertz, F.H., 2008. Integrative approaches to the study of primate infectious disease: implications for biodiversity conservation and global health. Am. J. Phys. Anthropol. 137 (S47), 53-69.

Gogarten, J.F., Brown, L.M., Chapman, C.A., Cords, M., Doran-Sheehy, D.M., Fedigan, L.M., Grine, F.E., Perry, S., Pusey, A.E., Sterck, E.H.M., et al., 2012. Seasonal mortality patterns in non-human primates: implications for variation in selection pressures across environments. Evolution 66, 3252-3266. 
Goldberg, T.L., Gillespie, T.R., Rwego, I.B., Estoff, E.L., Chapman, C.A., 2008. Forest fragmentation as cause of bacterial transmission among nonhuman primates, humans, and livestock, Uganda. Emerg. Infect. Dis. 14 (9), 1375-1382.

Goldberg, T.L., Gillespie, T.R., Rwego, I.B., Wheeler, E., Estoff, E.L., Chapman, C.A., 2007. Patterns of gastrointestinal bacterial exchange between chimpanzees and humans involved in research and tourism in western Uganda. Biol. Conserv. 135, 517.

Gomez, A., Petrzelkova, K., Yeoman, C., Vlckoav, K., Mrazek, J., Koppova, I., Carbonero, F., Ulanov, A., Modry, D., Todd, A., et al., 2015a. Gut microbiome composition and metabolomic profiles of wild western lowland gorillas (Gorilla gorilla gorilla) reflect host ecology. Mol. Ecol. 24, 2551-2565.

Gomez, A., Rothman, J.M., Petrzelkova, K., Yeoman, C.J., Vlckova, K., Umaña, J.D., Carr, M., Modry, D., Todd, A., Torralba, M., et al., 2016. Temporal variation selects for dietmicrobe co-metabolic traits in the gut of Gorilla spp. Int. Soc. Microb. Ecol. J. 10, 514-526.

Gore, M.A., Brandes, F., Kaup, FJ., Lenzner, R., Mothes, T., Osman, A.A., 2001. Callitrichic nutrition and food sensitivity. J. Med. Primatol. 30, 179-184.

Gough, E., Shaikh, H., Manges, A.R., 2011. Systematic review of intestinal microbiota transplantation (fecal bacteriotherapy) for recurrent Clostridium difficile infection. Clin. Infect. Dis. 53 (10), 994-1002.

Grenham, S., Clarke, G., Cryan, J.F., Dinan, T.G., 2011. Brain-gut-microbe communication in health and disease. Front. Physiol. 2, 94. http://dx.doi.org/10.3389/fphys.2011.00094.

Hale, V.L., Tan, C.L., Knight, R., Amato, K.R., 2015. Effect of preservation method on spide monkey (Ateles geoffroyi) fecal microbiota over 8weeks. J. Microbiol. Methods 113, $16-26$.

Harper, K.N., Fyumagwa, R.D., Hoare, R., Wambura, P.N., Coppenhaver, D.H., Sapolsky, R.M., SC, A., Tung, J., Rogers, J., Kilewo, M., Batamuzi, E.K., Leendertz, F.H. Armelagos, G.J., Knauf, S., 2012. Treponema pallidum infection in the wild baboons of East Africa: distribution and genetic characterization of the strains responsible. PLoS One 7 (12), e50882.

Heijtz, R., Wang, S., Anuar, F., Qian, Y., Bjorkholm, B., Samuelsson, A., Hibberd, M.L., Forssberg, H., Pettersson, S., 2011. Normal gut microbiota modulates brain development and behavior. Proc. Natl. Acad. Sci. U. S. A. 108, 3047-3052.

Hawrelak, J.A., Myers, S.P., 2004. The causes of intestinal dysbiosis: a review. Altern. Med. Rev. 9 (2), 180-197.

Hehemann, J.H., Correc, G., Barbeyron, T., Helbert, W., Czjzek, M., Michel, G., 2010. Transfer of carbohydrate-active enzymes from marine bacteria to Japanese gut microbiota. Nature 464, 908-912.

Holzmann, I., Agostini, I., Areta, J.I., Ferreyra, H., Beldomenico, P., Di Bitetti, M.S., 2010. Impact of yellow fever outbreaks on two howler monkey species (Alouatta guarib clamitans and A. caraya) in Misiones, Argentina. Am. J. Primatol. 72 (6), 475-480.

Hooper, L.V., Littman, D.R., Macpherson, A.J., 2012. Interactions between the microbiota and the immune system. Science 336, 1268-1273.

Human Microbiome Project Consortium, 2012. Structure, function and diversity of the healthy human microbiome. Nature 486, 207-214.

Huycke, M.M., Gaskins, H.R., 2004. Commensal bacteria, redox stress, and colorectal cancer: mechanisms and models. Exp. Biol. Med. 229 (7), 586-597.

IUCN, 1993. Environmental Synopsis 1993: Sierra Leone.

Ivanov, I.L., Atarashi, K., Manel, N., Brodie, E.L., Shima, T., Karaoz, U., Wei, D., Goldfarb, K.C Santee, C.A., Lynch, S.V., et al., 2009. Induction of Th17 cells by segmented filamentous bacteria. Cell Press 139, 485-498.

Janssen, D.L., 1994. Morbidity and mortality of Douc langurs (Pygathrix nemaeus) at the San Diego Zoo. Proceedings of the American Association of Zoo Veterinarians, pp. 221-226.

Jones, K.E., Patel, N.G., Levy, M.A., Storeygard, A., Balk, D., Gittleman, J.L., Daszak, P., 2008. Global trends in emerging infectious diseases. Nature 451 (7181), 990-993.

Karsenty, A., 2007. Overview of Industrial Forest Concessions and Concession-based Industry in Central and West Africa and Considerations of Alternatives. Rights and Resources Initiative, Washington, D.C., USA.

Kau, A.L., Abern, P.P., Griffin, N.W., Goodman, A.L., Gordon, J.I., 2011. Human nutrition, the gut microbiome and the immune system. Nature 474, 327-336.

Keele, B.F., Heuverswyn, F.V., Li, Y., Bailes, E., Takehisa, J., Santiago, M.L., Bibollet-Ruche, F. Chen, Y., Wain, L.V., Liegeois, F., et al., 2006. Chimpanzee reservoirs of pandemic and nonpandemic HIV-1. Science 313, 523-526.

Kim, T.K., Thomas, S.M., Ho, M., Sharma, S., Reich, C.I., Frank, J.A., et al., 2009. Heterogeneity of vaginal microbial communities within individuals. J. Clin. Microbiol. 47, 1181-1189.

Klailova, M., Hodgkinson, C., Lee, P.C., 2010. Behavioral responses of one western lowland gorilla (Gorilla gorilla gorilla) group at Bai Hokou, Central African Republic, to tourists, researchers and trackers. Am. J. Primatol. 72 (10), 897-906.

Koch, H., Schmid-Hempel, P., 2011a. Bacterial communities in central European bumblebees: low diversity and high specificity. Microb. Ecol. 62, 121-133.

Koch, H., Schmid-Hempel, P., 2011b. Socially transmitted gut microbiota protect bumble bees against an intestinal parasite. Proc. Natl. Acad. Sci. 108, 19288-19292.

Kohl, K.D., Skopec, M.M., Dearing, M.D., 2014. Captivity results in disparate loss of gut microbial diversity in closely related hosts. Conserv. Physiol. 2. http://dx.doi.org/10 1093/conphys/cou009.

Kondgen, S., Kuhl, H., N'Goran, P.K., Walsh, P.D., Schenk, S., Ernst, N., Biek, R., Formenty, P., Matz-Rensing, K., Schweiger, B., et al., 2008. Pandemic human viruses cause decline of endangered great apes. Curr. Biol. 18, 260-264.

Laurenson, K., Sillero-Zubiri, C., Thompson, H., Shiferaw, F., Thirgood, S., Malcolm, J., 1998. Disease as a threat to endangered species: Ethiopian wolves, domestic dogs and canine pathogens. Anim. Conserv. 1 (4), 273-280.

LeBlanc, J.G., Milani, C., de Giori, G.S., Sesma, F., van Sinderen, D., Ventura, M., 2013. Bacteria as vitamin suppliers to their host: a gut microbiota perspective. Curr. Opin. Biotechnol. 24 (2), 160-168.

Le Guenno, B., Formenty, P., Wyers, M., Gounon, P., Walker, F., Boesch, C., 1995. Isolation and partial characterisation of a new strain of Ebola virus. Lancet 345, 1271-1274.
Lee, Y.K., Mazmanian, S.K., 2010. Has the microbiota played a critical role in the evolution of the adaptive immune system? Science 330, 1768-1773.

Leendertz, F.H., Junglen, S., Boesch, C., Formenty, P., Couacy-Hymann, E., Courgnaud, V., Pauli, G., Ellerbrok, H., 2004. High variety of different simian T-cell leukemia virus type 1 strains in chimpanzees (Pan troglodytes verus) of the Tai National Park Cote d'Ivoire. J. Virol. 78, 4352-4356.

Leendertz, F.H., Pauli, G., Maetz-Rensing, K., Boardman, W., Nunn, C., Ellerbrok, H., Jensen, S.A., Junglen, S., Christophe, B., 2006. Pathogens as drivers of population declines: the importance of systematic monitoring in great apes and other threatened mammals. Biol. Conserv. 131, 325-337.

Leroy, E.M., Rouquet, P., Formenty, P., Souquière, S., Kilbourne, A., Froment, J., Bermejo, M., Smit, S., Karesh, W., Swanepoel, R., et al., 2004. Multiple Ebola virus transmission events and rapid decline of central African wildlife. Science 303, 387-390.

Less, E.H., Lukas, K.E., Bergl, R., Ball, R., Kuhar, C.W., Lavin, S.R., Raghanti, M.A., Wensvoort, J., Willis, M.A., Dennis, P.M., 2014. Implementing a low-starch, biscuit-free diet in zoo gorillas: the impact on health. Zoo Biol. 33, 74-80.

Ley, R.E., Hamady, M., Lozupone, C., Turnbaugh, P.J., Ramey, R.R., Bircher, J.S., Schlegel, M.L., Tucker, T.A., Schrenzel, M.D., Knight, R., et al., 2008. Evolution of mammals and their gut microbes. Science 320, 1647-1651.

Ley, R.E., 2010. Obesity and the human microbiome. Curr. Opin. Gastroenterol. 26 (1), 5-11.

Li, K., Bihan, M., Yooseph, S., Methé, B.A., 2012. Analyses of the microbial diversity across the human microbiome. PLoS One 7 (6), e32118. http://dx.doi.org/10.1371/journal. pone.0032118.

Lonsdorf, E.V., Travis, D., Pusey, A.E., Goodall, J., 2006. Using retrospective health data from the Gombe chimpanzee study to inform future monitoring efforts. Am. J. Primatol. 68, 897-908.

Lopetuso, L.R., Scaldaferri, F., Petito, V., Gasbarrini, A., 2013. Commensal clostridia: leading players in the maintenance of gut homeostasis. Gut Pathog. 5, 23.

Lozupone, C.A., Stombaugh, J.I., Gordon, J.I., Jansson, J.K., Knight, R., 2012. Diversity, stability and resilience of the human gut microbiota. Nature 489 (7415), 220-230.

Macfarlane, S., Macfarlane, G.T., 2003. Regulation of short-chain fatty acid production. Proc. Nutr. Soc. 62 (1), 67-72.

Mazmanian, S.K., Round, J.L., Kasper, D.L., 2008. A microbial symbiosis factor prevents intestinal inflammatory disease. Science 453, 620-625.

Mech, S.G., Hallett, J.G., 2001. Evaluating the effectiveness of corridors: a genetic approach. Conserv. Biol. 15, 467-474.

Milton, K., 1986. Ecological background and conservation priorities for woolly spider monkeys (Brachyteles arachnoides). In: Benirschke, K. (Ed.), Primates-the Road to Self-sustaining Populations. Springer-Verlag, New York, pp. 241-250.

Mire, C.E., Matassov, D., Geisbert, J.B., Latham, T.E., Agans, K.N., Xu, R., Ota-Setlik, A., Egan, M.A., Fenton, K.A., Clarke, D.K., et al., 2015. Single-dose attenuated Vesiculovax vaccines protect primates against Ebola Makona virus. Nature 520, 688-691.

Moeller, A.H., Peeters, M., Ndjango, J.B., Li, Y., Hahn, B.H., Ochman, H., 2013. Sympatric chimpanzees and gorillas harbor convergent gut microbial communities. Genome Res. 23 (10), 1715-1720.

Moran, N.A., McCutcheon, J.P., Nakabachi, A., 2008. Genomics and evolution of heritable bacterial symbionts. Annu. Rev. Genet. 42, 165-190.

Muegge, B.D., Kuczynski, J., Knights, D., Clemente, J.C., Gonzalez, A., Fontana, L., Henrissat, B., Knight, R., Gordon, J.I., 2011. Diet drives convergence in gut microbiome functions across mammalian phylogeny and within humans. Science 332, 970-974.

Nijboer, J., Clauss, M., Everts, H., Beynen, A.C., 2006. Effect of dietary fibre on the faeces score in colobine monkeys at Dutch Zoos. In: Fidgett, A Clauss, M, Eulenberger, K, Hatt, J.M., Hume, I., Janssens, G., Nijboer, J. (Eds.), Zoo Animal Nutrition vol. III. Filander, Furth, pp. 145-155.

Oates, J.F., Davies, A.G. (Eds.), 1994. Colobine monkeys: Their Ecology, Behaviour, and Evolution. Cambridge University Press.

Palacios, G., Lowenstine, L.J., Cranfield, M.R., Gilardi, K.V., Spelman, L., Lukasik-Braum, M., Kinani, J.F., Mudakikwa, A., Nyirakaragire, E., et al., 2011. Human Metapneumovirus infection in wild mountain gorillas, Rwanda. Emerg. Infect. Dis. 17, 711-713.

Pedersen, A.B., Altizer, S., Poss, M., Cunningham, A.A., Nunn, C.L., 2005. Patterns of host specificity and transmission among parasites of wild primates. Int. J. Parasitol. 35 (6), 647-657.

Peterson, J., Garges, S., Giovanni, M., McInnes, P., Wang, L., Schloss, J.A., Baker, C.C., 2009. The NIH human microbiome project. Genome Res. 19 (12), 2317-2323.

Phillips, C.D., et al., 2012. Microbiome analysis among bats describes influences of host phylogeny, life history, physiology and geography. Mol. Ecol. 21, 2617-2627.

Pope, T.R., 1998. Genetic variation in remnant populations of the woolly spider monkey (Brachyteles arachnoides). Am. J. Primatol. 19, 95-109.

Popovich, D.G., Jenkins, D.J., Kendall, C.W., Dierenfeld, E.S., Carroll, R.W., Tariq, N., Vidgen, E., 1997. The western lowland gorilla diet has implications for the health of humans and other hominoids. J. Nutr. 127 (10), 2000-2005.

Qin, J., Li, R., Raes, J., Arumugam, M., Burgdorf, K.S., Manichanh, C., ... Mende, D.R., 2010. A human gut microbial gene catalogue established by metagenomic sequencing. Nature 464, 59-65.

Rakoff-Nahoum, S., Paglino, J., Eslami-Varzaneh, F., Edberg, S., Medzhitov, R., 2004. Recognition of commensal microflora by toll-like receptors is required for intestinal homeostasis. Cell Press 118, 229-241.

Rangel-Negrín, A., Alfaro, J.L., Valdez, R.A., Romano, M.C., Serio-Silva, J.C., 2009. Stress in Yucatan spider monkeys: effects of environmental conditions on fecal cortisol levels in wild and captive populations. Anim. Conserv. 12, 496-502.

Ravel, J., Gajer, P., Abdo, Z., Schneider, G.M., Koenig, S.S., McCulle, S.L., Karlebach, S., Gorle, R., Russell, J., Tacket, C.O., et al., 2011. Vaginal microbiome of reproductive-age women. Proc. Natl. Acad. Sci. U. S. A. 108 (Supplement 1), 4680-4687.

Redford, K.H., Segre, J.A., Salafsky, N., Martinez del Rio, C., McAloose, D., 2012. Conservation and the microbiome. Conserv. Biol. 26, 195-197. 
Rosenberg, D.K., Noon, B.R., Meslow, E.C., 1997. Biological corridors: form, function, and efficacy. Bioscience 47, 677-687.

Rosenberg, E., Sharon, G., Atad, I., Zilber-Rosenberg, I., 2010. The evolution of animals and plants via symbiosis with microorganisms. Environ. Microbiol. Rep. 2, 500-506.

Round, J.L., Mazmanian, S.K., 2009. The gut microbiota shapes intestinal immune responses during health and disease. Nat. Rev. Immunol. 9, 313-323.

Rouquet, P., Froment, J.M., Bermejo, M., Kilbourn, A., Karesh, W.B., Reed, P., Kumulungui, B., Yaba, P., Delicat, A., Rollin, P.E., et al., 2005. Wild animal mortality monitoring and human Ebola outbreaks, Gabon and Republic of Congo, 2001-2003. Emerg. Infect. Dis. $11,283-290$.

Rushmore, J., Caillaud, D., Matamba, L., Stumpf, R.M., Borgatti, S.P., Altizer, S., 2013. Social network analysis of wild chimpanzees with insights for disease transmission. J. Anim. Ecol. 82, 976-986.

Rwego, I.B., Isabirye-Basuta, G., Gillespie, T.R., Goldberg, T.L., 2008. Gastrointestinal bacterial transmission among humans, mountain gorillas, and livestock in Bwindi Impenetrable National Park, Uganda. Conserv. Biol. 22, 1600-1607.

Ryan, S.J., Walsh, P.D., 2011. Consequences of non-intervention for infectious disease in African great apes. PLoS One 6, e29030. http://dx.doi.org/10.1371/journal.pone. 0029030 .

Sak, B., Petrzelkova, K.J., Kvetonova, D., Mynarova, A., Shutt, K.A., Pomajbikova, K., Kalousova, B., Modry, D., Benavides, J., Todd, A., Kvac, M., 2013. Long-term monitoring of microsporidia, Cryptosporidium and Giardia infections in western lowland gorillas (Gorilla gorilla gorilla) at different stages of habituation in Dzanga Sangha Protected Areas, Central African Republic. PloS one 8 (8), e71840.

Samuel, B.S., Shaito, A., Motoike, T., Rey, F.E., Backhed, F., Manchester, J.K., Hammer, R.E., Williams, S.C., Crowley, J., Yanagisawa, M., Gordon, J.I., 2008. Effects of the gut microbiota on host adiposity are modulated by the short-chain fatty-acid binding $\mathrm{G}$ protein-coupled receptor, Gpr41. Proc. Natl. Acad. Sci. 105 (43), 16767-16772.

Savage, D.S., 1977. Microbial ecology of the gastrointestinal tract. Annu. Rev. Microbiol. 31, 107-133.

Schachtschneider, K.M., Yeoman, C.J., Isaacson, R.E., White, B.A., Schook, L.B., Pieters, M., 2013. Modulation of systemic immune responses through commensal gastrointestinal microbiota. PLoS One 8, e56111.

Sekirov, I., Russell, S.L., Antunes, L.C.M., Finlay, B.B., 2010. Gut microbiota in health and disease. Physiol. Rev. 90 (3), 859-904.

Singh, Y., Ahmad, J., Musarrat, J., Ehtesham, N.Z., Hasnain, S.E., 2013. Emerging importance of holobionts in evolution and in probiotics. Gut Pathogens 5, 12.

Soorae, P.S. (Ed.), 2011. Global Re-introduction Perspectives: 2011. More Case Studies from Around the Globe. Gland, Switzerland: IUCN/SSC Re-introduction Specialist Group and Abu Dhabi. Environment Agency-Abu Dhabi, UAE.

Serino, M., Luche, E., Gres, S., Baylac, A., Bergé, M., Cenac, C., Waget, A., Klopp, P., Iacovoni, J., Klopp, C., Mariette, J., 2012. Metabolic adaptation to a high-fat diet is associated with a change in the gut microbiota. Gut 61 (4), 543-553.

Stamps, J.A., Swaisgood, R.R., 2007. Someplace like home: experience, habitat selection and conservation biology. Appl. Anim. Behav. Sci. 102 (3-4), 392-409.

Stanley, D.A., Honko, A.N., Asiedu, C., Trefry, J.C., Lau-Kilby, A.W., Johnson, J.C., Hensley, L. Ammendola, V., Abbate, A., Grazioli, F., et al., 2014. Chimpanzee adenovirus vaccine generates acute and durable protective immunity against ebolavirus challenge. Nat. Med. 20, 1126-1129.

Stem, C., Margoluis, R., Salafsky, N., Brown, M., 2005. Monitoring and evaluation in conservation: a review of trends and approaches. Conserv. Biol. 19, 295-309.

Stevens, C.E., Hume, I.D., 1998. Contributions of microbes in vertebrate gastrointestinal tract to production and conservation of nutrients. Physiol. Rev. 78 (2), 393-427.

Stiles, D., 2014. How did the Ebola Zaire get to Guinea? Mongabey.com (5th August 2014)

Stumpf, R.M., Thompson, M.E., Muller, M.N., Wrangham, R.W., 2009. The context of female dispersal in Kanyawara chimpanzees. Behaviour 146 (4), 629-656.

Stumpf, R.M., Wilson, B.A., Rivera, A., Yildirim, S., Yeoman, C.J., Polk, J.D., White, B.A., Leigh S.R., 2013. The primate vaginal microbiome: comparative context and implications for human health and disease. Am. J. Phys. Anthropol. 152 (S57), 119-134.

Swartz, J.D., Lachman, M., Westveer, K., O'Neill, T., Geary, T., Kott, R.W., Berardinelli, J.G., Hatfield, P.G., Thomson, J.M., Roberts, A., et al., 2014. Characterization of the vaginal microbiota of ewes and cows reveals a unique microbiota with low levels of lactobacilli and near-neutral pH. Front. Vet. Sci. 1, 19.
Taylor, L.K., Latham, S.M., Woolhouse, M.E., 2001. Risk factors for human disease emergence. Philos. Trans. R. Soc. Lond. Ser. B Biol. Sci. 356, 983-989.

Tung, J., Barreiro, L.B., Burns, M.B., Grenier, J.C., Lynch, J., Grieneisen, L.E., Altmann, J., Alberts, S.C., Blekhman, R., Archie, E.A., 2015. Social networks predict gut microbiome composition in wild baboons. eLife 4, e05224.

Tremaroli, V.[.J.P1]., Bäckhed, F., 2012. Functional interactions between the gut microbiota and host metabolism. Nature 489, 242-249.

Turnbaugh, P.J., Ley, R.E., Mahowald, M.A., Magrini, V., Mardis, E.R., Gordon, J.I., 2006. An obesity-associated gut microbiome with increased capacity for energy harvest. Nature 444, 1027-1031.

Turnbaugh, P.J., Ridaura, V.K., Faith, J.J., Rey, F.E., Knight, R., Gordon, H.A., 2009. The effect of diet on the human gut microbiome: a metagenomic analysis in humanized gnotobiotic mice. Sci. Transl. Med. 1, 6ra14.

Van Belle, S., Estrada, A., 2006. Demographic features of Alouatta pigra populations in extensive and fragmented forests. In New perspectives in the study of Mesoamerican primates. Springer, US, pp. 121-142.

Vlčková, K., Gomez, A., Petrželková, K.J., Whittier, C.A., Todd, A., Nelson, K., Wilson, B.A. Stumpf, R.M., Modrý, D., White, B.A., Leigh, S.R., 2016. Effect of antibiotic treatment on the gastrointestinal microbiota of free-ranging western lowland gorillas (Gorilla G. gorilla). Microb. Ecol. PMID: 26984253.

Vaishnava, S., Behrendt, C.L., Ismail, A.S., Eckmann, L., Hooper, L.V., 2008. Paneth cells directly sense gut commensals and maintain homeostasis at the intestinal host-microbial interface. Proc. Natl. Acad. Sci. 105 (52), 20858-20863.

Walsh, P.D., Abernethy, K.A., Bermejo, M., Beyersk, R., De Wachter, P., Akou, M.E., Huijbregts, B., Mambuonga, D.I., Toham, A.K., Kilbourn, A.M., et al., 2003. Catastrophic ape decline in western equatorial Africa. Nature 422, 611-614.

Walsh, P.D., Biek, R., Real, L.A., 2005. Wave-like spread of Ebola Zaire. PLoS Biol. 3, e371.

Warfield, K.L., Goetzmann, J.E., Biggins, J.E., Kasda, M.B., Unfer, R.C., Vu, H., Aman, M.J. Olinger, G.G., Walsh, P.D., 2014. Vaccinating captive chimpanzees to save wild chimpanzees. Proc. Natl. Acad. Sci. 111, 8873-8876.

Williams, C.L., Willard, S., Kouba, A., Sparks, D., Holmes, W., Falcone, J., Williams, C.H. Brown, A., 2012. Dietary shifts affect the gastrointestinal microflora of the giant panda (Ailuropoda melanoleuca). J. Anim. Physiol. Anim. Nutr. 97, 577-585.

Williams, J.M., Lonsdorf, E.V., Wilson, M.L., Schumacher-Stankey, J., Goodall, J., Pusey, A.E. 2008. Causes of death in the Kasekela chimpanzees of Gombe National Park, Tanzania. Am. J. Primatol. 70, 766-777.

Wood, J.L., Leach, M., Waldman, L., MacGregor, H., Fooks, A.R., Jones, K.E., Restif, O. Dechmann, D., Hayman, D.T., Baker, K.S., Peel, A.J., 2012. A framework for the study of zoonotic disease emergence and its drivers: spillover of bat pathogens as a case study. Philos. Trans. R. Soc. Lond. B 367 (1604), 2881-2892.

Yatsunenko, T., Rey, F.E., Manary, M.J., Trehan, I., Dominguez-Bello, M.G., Contreras, M. Magris, M., Hidalgo, G.L., Galdassano, R.N., Anokhin, A.P., et al., 2012. Human gut microbiome viewed across age and geography. Nature 486, 222-228.

Yeoman, C.J., Chia, N., Yildirim, S., Berg Miller, M.E., Kent, A., Stumpf, R., Leigh, S.R., Nelson, K.E., White, B.A., Wilson, B.A., 2011. Towards an evolutionary model of animalassociated microbiomes. Entropy 13, 570-594.

Yeoman, C.J., Thomas, S.M., Miller, M.E.B., Ulanov, A.V., Torralba, M., Lucas, S., Gillis, M., Cregger, M., Gomez, A., Ho, M., Leigh, S.R., 2013. A multi-omic systems-based approach reveals metabolic markers of bacterial vaginosis and insight into the disease. PLoS One 8 (2), e56111.

Yildirim, S., Yeoman, C.J., Sipos, M., Torralba, M., Wilson, B.A., Goldberg, T.L., Stumpf, R.M., Leigh, S.R., White, B.A., Nelson, K.E., 2010. Characterization of the fecal microbiome from non-human wild primates reveals species specific microbial communities. PloS one 5 (11), e13963.

Zilber-Rosenberg, I., Rosenberg, E., 2008. Role of microorganisms in the evolution of animals and plants: the hologenome theory of evolution. FEMS Microbiol. Rev. 32, 723-735.

Zobaníková, M., Strouhal, M., Mikalová, L., Cejková, D., Ambrožová, L., Pospíšilová, P. Fulton, L.L., Chen, L., Sodergren, E., Weinstock, G.M., Smajs, D., 2013. Whole genome sequence of the Treponema Fribourg-Blanc: unspecified simian isolate is highly similar to the yaws subspecies. PLoS Negl. Trop. Dis. 7 (4), e2172. 